\title{
Oral contraceptives and oral antibiotics: interactions and advice in an accident and emergency setting
}

\author{
Michelle H Mullan, Adrian R Harris
}

\begin{abstract}
Objective-(1)To determine what advice, if any, would be given by accident and emergency $(A \& E)$ doctors to women who were taking the combined oral contraceptive pill (OCP) if they had been issued with broad spectrum antibiotics and (2) after an audit programme had been instigated, whether appropriate advice was given to such women.

Methods-A questionnaire was circulated to 12 doctors working in the Exeter A\&E department to assess their level of knowledge in prescribing antibiotics to women taking the OCP. Notes of women aged 15-50 who had been prescribed broad spectrum antibiotics were examined to see if a contraceptive history had been taken. If the patient was found to be taking the combined OCP it was noted whether documented advice had been given about using an additional form of contraception. Six months later after two education sessions had been held, prescriptions and notes were examined. A patient education leaflet was produced to be given to these women, indicating what additional precautions should be taken after having been prescribed antibiotics.
\end{abstract}

Setting-The A\&E department of a busy district general hospital.

Subjects-Women aged 15-50 who had been issued with broad spectrum antibiotics.

Results-The level of knowledge in regard to contraceptive advice given to women taking the OCP among doctors working in an A\&E department was poor. However, after educational sessions and the production of a patient information leaflet, there was an improvement in women receiving correct advice.

Conclusions-The clinical significance of drug interactions between oral contraceptives and antibiotics indicates the importance of asking a full contraceptive drug history of any woman of childbearing age and documenting this in the notes. Regular audit of this topic is needed to keep it at the front of doctors' minds. $(\mathcal{F}$ Accid Emerg Med 1999;16:265-267)

Keywords: antibiotics; contraception; pregnancy

Correspondence to:

Directorate of

urgery,

Bristol Royal Infirmary,

Bristol BS2 8HW.

Accepted 11 February 1999
The combined oral contraceptive pill (OCP) is a popular form of contraception for women world wide. The period between the early 1960s and mid-1970s saw a marked decline in mechanical methods of contraception and dramatic increase in the use of hormonal methods. It is estimated that $25 \%$ of women aged $16-49$ in the UK are regular users of the OCP, ${ }^{1}$ with up to $95 \%$ of sexually active women under 30 having used this method at some time. ${ }^{2} \mathrm{~A}$ smaller but more recent study of 1000 women aged 16-44 estimated one in three women use the OCP. ${ }^{3}$

The combined OCP is a preparation containing both oestrogen and progestogen that is taken daily for three weeks, followed by a pill free week when the woman undergoes a withdrawal bleed. Some pill packets contain seven "sugar pills" so the woman does not get out of the habit of tablet taking. The oestrogens inhibit ovulation and the progesterones induce endometrial and genital tract changes making implantation unlikely. The cervical mucus also becomes unusually viscous thus inhibiting spermatozoa.

In this increasingly litigious world where doctors and dentists may be sued if patients become pregnant shortly after a course of antibiotics, it is a topic of importance for all prescribers. The dental world has been more vigilant of late ${ }^{45}$ as an American dentist was successfully sued by a patient who became pregnant shortly after finishing a course of antibiotics. $^{6}$ This issue is of tremendous importance for doctors working in an accident and emergency (A\&E) department where broad spectrum antibiotics are frequently prescribed. Doctors should be aware that women are susceptible to becoming pregnant if taking both the OCP and antibiotics, thus being able to offer appropriate advice to women of childbearing age.

\section{Standards}

The Family Planning Association in the British National Formulary states that: "additional contraceptive precautions should be taken whilst taking a short course of a broad spectrum antibiotic and for 7 days after stopping. If these 7 days run beyond the end of a packet the next packet should be started immediately without a break (in the case of the everyday tablets the inactive ones should be omitted). If the course exceeds 2 weeks, the bacterial flora develops antibiotic resistance and additional precautions become unnecessary". ${ }^{7}$ 
Table 1 Adequacy of advice given by doctors ( $n=12)$; values are number (\%)

\begin{tabular}{lllll}
\hline Grade & No advice & $\begin{array}{l}\text { Incorrect } \\
\text { advice }\end{array}$ & $\begin{array}{l}\text { Inadequate } \\
\text { advice }\end{array}$ & $\begin{array}{l}\text { Correct } \\
\text { advice }\end{array}$ \\
\hline $\begin{array}{l}\text { Consultants }(\mathrm{n}=2 \text { males) } \\
\text { Male middle grades }(\mathrm{n}=4)\end{array}$ & $1(8.3)$ & $1(8.3)$ & $\begin{array}{l}2(16.7) \\
2(16.7)\end{array}$ & \\
$\begin{array}{l}\text { Female middle grades }(\mathrm{n}=2) \\
\text { Male SHO/GP trainees }(\mathrm{n}=2)\end{array}$ & & & $1(8.3)$ & $\begin{array}{l}1(8.3) \\
2(16.7)\end{array}$ \\
Female SHO/GP trainees $(\mathrm{n}=2)$ & & & & $2(16.7)$ \\
\hline
\end{tabular}

\section{Methods}

QUESTIONNAIRE

We designed a simple questionnaire, which was completed by 12 doctors in the department comprising senior house officers (SHOs), registrars, those at staff grade, and consultants.

The questions looked at what advice would be given to women who had been issued with a broad spectrum antibiotic if they were currently taking the OCP; what advice would be given in relation to running two pill packets back to back if the woman was near the end of her pill packet, and would finish the antibiotics while in her "pill free week", and if doctors recorded advice given in the $A \& E$ notes. The final question asked if doctors felt a patient information leaflet would be a good idea.

\section{Results}

\section{QUESTIONNAIRE}

The adequacy of advice given by each grade of doctor was classified into one of four categories (see table 1).

Five of the 12 doctors $(41.7 \%)$ gave correct advice, telling women to use additional contraception while on the antibiotics and for seven days after. One gave incorrect advice, five gave inadequate advice, and one gave no advice at all. Only five knew that women should run two packets of pills back to back if a woman was nearly at the end of her pill packet, therefore missing out the pill free week. Ten of the 12 $(83.0 \%)$ reported that they always or usually recorded if they had given advice in the notes. All doctors questioned felt that a patient information leaflet would be a good idea. Of note, the better marks were obtained by general practice (GP) trainees and female members of staff.

\section{AUDIT OF MARCH 1997 PRESCRIPTIONS}

Prescriptions issued by the $A \& E$ department to women between the ages of 15 and 50 who had been prescribed antibiotics were identified and the relevant case notes were checked. It was noted if a drug history had been asked and secondly if they were on the OCP, whether additional contraceptive advice had been given.

Of the 21 women aged 15-50 who had been prescribed antibiotics, nine $(43.0 \%)$ had a drug history recorded and only two $(9.5 \%)$ had received documented contraceptive advice.

A teaching session was organised in the department targeting both doctors and nurses, emphasising the national guidelines. This information was produced in a written form and kept in the departmental guidelines, easily accessible in the department. A patient education leaflet was produced, which was given to women at the time the prescription was written, detailing advice and recommendations on alternative methods of contraception. The address and telephone number of the local Family Planning Association were also included.

REAUDIT AND EVALUATION

Prescriptions from September 1997 were examined to see if there had been an improvement in whether a contraceptive history had been taken from women aged $15-50$ receiving prescriptions for a broad spectrum antibiotic and, if applicable, whether a patient information leaflet had been issued.

Altogether 367 prescriptions had been written, with 19 women of the appropriate ages receiving scripts for antibiotics. Eleven of these had been asked a drug history and only four were taking the OCP. All four had been issued with an advice leaflet.

\section{Discussion}

ANTIBIOTICS AND OCP FAILURE

Expected rates of failure for the OCP are between 0.1 and 1.0 pregnancies per 100 woman years (that is, if 100 women took the OCP perfectly for one year there would be at most one pregnancy). There is a large quantity of literature on drug interactions involving the combined OCP, with broad spectrum antibiotics being implicated in failure of contraception in women already using the OCP. ${ }^{689}$

Broad spectrum antibiotics are thought to reduce the effectiveness of the OCP through various means. ${ }^{4-68}$ The three most accepted theories are: firstly increasing urinary or faecal excretion of oestrogens (perhaps antibiotic induced diarrhoea); secondly by stimulated induction of hepatic metabolism of oestrogens or progesterones (for example rifampicin); and finally if bacterial deconjugation of the oestrogen is prevented (particularly by broad spectrum antibiotics), plasma concentrations of active hormone are reduced.

\section{EVIDENCE}

In this world of increasingly evidence based medicine, ${ }^{9}$ it is difficult to find good randomised controlled trials on this subject. Most of the evidence has come from individual case reports and evaluation of the "yellow card" reports sent in to the Committee on Safety of Medicines. Back et al looked at the yellow card reports between 1968-84 and found 63 pregnancies in women who had been coprescribed antibiotics while taking the OCP. ${ }^{10}$ Seventy per cent (44/63) of these women were taking either a penicillin or tetracycline. More up to date figures from the Committee on Safety of Medicines indicate there have now been 136 pregnancies reported between 1968 to August 1997 (personal communication).

This audit highlights the fact that anyone involved in prescribing broad spectrum antibiotics to women of childbearing age should always ask a contraceptive history and, if appropriate, issue the patient with advice on additional forms of contraception while she is taking the antibiotic and for seven days afterwards. The benefit of a patient information leaflet means that the patient has a 


\section{Box 1: Antibiotics and the oral contraceptive pill}

Women who are taking the oral contraceptive pill should be aware that some antibiotics can make the contraceptive pill less effective.

You are advised to use extra contraceptive methods (condoms or cap plus spermicide) while taking your course of antibiotics and for seven days after stopping. You should continue to take your contraceptive pill in the normal way.

If the days of using extra contraception run into your pill free week, start a new packet of pills as soon as you finish the current packet. Do not have the usual break. This will mean that you will not have a period, although you may get some light bleeding similar to a period (breakthrough bleeding) - this is not harmful.

If you have "everyday pills" miss out the seven inactive pills and start the next packet the day after taking the last active tablet of the current packet.

If you do not have a period after your second pack, you must talk to your general practitioner (or family planning clinic doctor) before you start the next pack.

If you have any concerns regarding the contents of this leaflet, please contact your general practitioner, family planning clinic, or accident and emergency.

written form of advice at home that reinforces the doctor's message, and a telephone number to ring if she requires further clarification.

One problem with this sort of audit is the difficulty of reminding doctors, who are often rotating round various departments, to offer contraceptive advice to women. Clearly senior colleagues should impress this information upon younger members of the team, with emphasis given to new junior doctors joining the department in February and August.

In this study, the group of four SHOs changed in August 1997, so the new SHOs did not benefit from the teaching. This could explain the disappointing fact that the number of drug histories had not significantly improved over the six months. Another explanation could be that doctors were under recording that appropriate advice had been given. It is interesting to note that the female members of staff and GP trainees had a heightened awareness of this subject. The study also emphasises that it is not just the SHOs who need educating, but it is important information for the senior members of the department to appreciate, so they can educate both the patients and the often junior SHOs.

Hospital pharmacies and staff nurses should also be involved in issuing advice and leaflets to women, so that if one person forgets, the message will be reinforced by another member of staff. It should be possible to have patient information leaflets available in the pharmacy, so when a prescription is given to the woman, a leaflet could also be given simultaneously. The information in the leaflet given out by the Royal Devon and Exeter Healthcare NHS Trust is shown in box 1 .

Our aim must be that no woman concurrently taking the combined OCP and broad spectrum antibiotics should be in any doubt as to what the correct options are in relation to contraception. There should be regular audit to highlight if departmental standards are slipping and to keep this topic at the forefront of doctors' minds.

Conflict of interest: none.

Funding: none.

1 Office of Population Censuses and Surveys. General household survey, 1993. London: HMSO, 1995.

2 Guillebaud J. Combined oral contraceptive pills. In: Loudon $\mathrm{N}$, ed. Handbook of family planning. Edinburgh: Churchill Livingstone, 1991: 63-123.

3 Schering Health Care. What women really think about sex and contraception. Survey carried out by National Opinion Polls on behalf of Schering Health Care (press release). Burgess Hill, West Sussex: Schering Health Care, 1993.

4 Stephens IFD, Kinane DF. Dentists, pills and pregnancies. Br Dent f 1996;181:236-9.

5 Gibson J, McGowan DA. Oral contraceptives and antibiotics: important considerations for dental practice. $\mathrm{Br}$ Dent $\mathcal{F} 1994 ; 177: 419-22$.

6 Shenfield GM. Oral contraceptives. Are drug interactions of clinical significance?. Drug Saf 1993;9:21-37.

7 Britsh Medical Association/Royal Pharmaceutical Society of Great Britain. British national formulary. London: Britsh Great Britain. British national formulary. London: Britsh Medical Association/Royal Pharmaceutical Great Britain, 1998, No 36 (September): 352.
8 Aronson J. Serious drug interactions. Practitioner 1993;237:

Sackett DL, Richardson WS, Rosenberg W, et al. Evidencebased medicine: how to practice and teach EBM. Edinburgh: Churchill Livingstone, 1997.

10 Back DJ, Grimmer SFM, Orme MLE, et al. Evaluation of Committee on Safety of Medicines yellow card reports on oral contraceptive-drug interactions with anti-convulsants and antibiotics. Br F Clin Pharmacol 1988;25:527-32. 